\title{
MICROSTRUCTURE OF SELECTIVE LASER MELTED TITANIUM LATTICES AND IN VITRO CELL BEHAVIOUR
}

\author{
1,2Laura HERNÁNDEZ-TAPIA, ${ }^{1}$ Azalia Mariel CARRANZA-TREJO, ${ }^{1}$ Adelia KASHIMBETOVA, \\ ${ }^{1}$ Serhii TKACHENKO, ${ }^{2} Z$ uzana KOLEDOVÁ, ${ }^{3}$ Daniel KOUTNÝ, ${ }^{3}$ Martin MALÝ, ${ }^{1}$ Ladislav ČELKO, \\ ${ }^{1}$ Edgar B. MONTUFAR
}

\author{
${ }^{1}$ CEITEC - Brno University of Technology, Brno, Czech Republic, EU, eb.montufar@ceitec.vutbr.cz \\ ${ }^{2}$ Faculty of Medicine, Masaryk University, Brno, Czech Republic, EU, koledova@med.muni.cz \\ ${ }^{3}$ Faculty of Mechanical Engineering, Brno University of Technology, Brno, Czech Republic, EU, \\ daniel.koutny@vut.cz
}

https://doi.org/10.37904/metal.2021.4259

\begin{abstract}
Selective laser melting (SLM) is a metal additive manufacturing technology that allows the fabrication of complex near-net-shape titanium parts. Among possible applications, titanium is important for the biomedical sector, in particular for orthopaedics due to its low elastic modulus, biocompatibility, high mechanical strength and corrosion resistance. Several studies show the structural properties and mechanical behaviour of titanium lattices that in parallel exhibited the porosity, mechanical strength and elastic modulus of trabecular bone. However, less attention has been devoted to study the biological response to titanium parts fabricated by SLM. Therefore, this work aimed to fabricate commercially pure titanium lattices by SLM and study the behaviour of bone-forming cells cultured on the lattices. The results show that Saos-2 osteoblast-like cells proliferated and covered the entire available surface of the titanium lattices becoming confluent and quiescent. The activity of alkaline phosphatase and the production of extracellular calcium deposits confirmed the growth of viable and mature osteoblasts. The cytocompatibility of the titanium lattices is an additional advantage that adds to the possibility to mimic the porosity and mechanical properties of bone by computer-aided design and subsequently implement the lattice fabrication by SLM, fitting the requirements of individual patients and, consequently, offering a broad range of new bone repair alternatives in orthopaedics.
\end{abstract}

Keywords: Selective laser melting, titanium, microstructure, osteoblast, cytocompatibility

\section{INTRODUCTION}

Selective laser melting (SLM) is a powder bed fusion metal-based additive manufacturing technology. The process consists of spreading a homogeneous layer of a metallic powder on the printing platform and afterwards lasers selectively melt the powder following a scanning path generated in silico specifically to build one cross-section of the object. The laser completely melts the powder, producing a solid and dense layer after solidification. Then, the printing platform lowers by the equivalent of one layer thickness, followed by automatic spreading of a new powder layer to build the next cross-section. The process is repeated layer by layer until the object is finalized. The whole process is performed under a protective inert gas atmosphere to prevent unwanted chemical reactions of the metal. Following these steps, SLM builds efficiently complex nearnet-shapes requiring little finishing, normally only the removal of the excess powder. Computer-aided design provides flexibility for the generation of the virtual model of the object and a specialized software provided with the SLM device mathematically slices the file and optimizes the paths of the lasers to prevent distortions due to thermal gradients, while it minimises the processing time. Several objects, even with different geometry and size, can be fabricated in parallel providing they fit in the area of the printing platform. The most commonly 
processed materials by SLM are steel, titanium and aluminium [1]. Titanium is in particular relevant for orthopaedic applications because it has high corrosion resistance, is biocompatible, and exhibits an elastic modulus closer to the elastic modulus of bone and below the modulus of other implantable metallic materials [2]. Therefore, titanium reduces the risk for the stress-shielding effect, which is one of the principal causes of implant failure due to bone resorption at the implant-bone interface [3]. In addition to its intrinsic low elastic modulus, the stiffness of titanium can be further reduced, down to the level of the trabecular human bone, by the fabrication of open porous structures, normally referred to as lattices in structural engineering or scaffolds in the field of tissue engineering. Complex titanium lattices have been built by SLM including fully triangulated lattices [4], triply periodic minimal surface structures [5], and functionally graded porous scaffolds [6]. Most of these studies provide the microstructural characterization and the evaluation of the mechanical performance of the structures, without addressing the biological behaviour. Consequently, the objective of this work was to produce commercially pure titanium lattices with an orthogonal grid pattern by SLM to study in vitro the proliferation, morphology, and maturation of bone-forming cells, osteoblasts. Monotonic and preliminary cyclic sinusoidal mechanical test were also performed.

\section{MATERIALS AND METHODS}

Commercially spherical pure titanium powder (ASTM Grade 1; TLS-Technik, Germany) was used for sample fabrication by SLM. The geometry of the samples was generated by computer-aided design, consisting of disclattices with a Cartesian grid pattern, with a diameter of $10 \mathrm{~mm}$ and a height of $3 \mathrm{~mm}$. The diameter of the struts forming the grid was set to $300 \mu \mathrm{m}$ (pore size in the printing plane of $500 \mu \mathrm{m}$ ). Samples were fabricated with a SLM $280 \mathrm{HL}$ machine (SLM Solutions AG, Germany) equipped with a $400 \mathrm{~W}$ ytterbium fibre laser with a Gaussian profile (YLR-400-WC-Y11, IPG Photonics, USA), working in the continuous wave mode. The samples were produced on an $80^{\circ} \mathrm{C}$ pre-heated platform, using laser power of $117 \mathrm{~W}$, scanning speed of 225 $\mathrm{mm} / \mathrm{s}$, hatch spacing of $90 \mu \mathrm{m}$, hatch offset of $20 \mu \mathrm{m}$, a layer thickness of $50 \mu \mathrm{m}$ and laser spot size of $82 \mu \mathrm{m}$ focused on the processing plane. High-purity argon was used as a protective gas at an over-pressure of 1.2 to $2.0 \mathrm{kPa}$ with an oxygen level of 0.1 to $0.3 \mathrm{vol} \%$. Samples were cleaned in an ultrasonic bath, then dried at room temperature and finally sterilized by gamma irradiation before to their use in cell culture (35 KGy). One sample was prepared for metallographic observation following standard methods for titanium. The microstructure was observed by a light microscope. The yield strength and elastic modulus under compression were determined by universal testing machine (Instron 8874) at a crosshead speed of $1 \mathrm{~mm} / \mathrm{min}$. Besides, a preliminary cyclic sinusoidal mechanical test was performed under compression at the stress ratio $R=10$ and maximum compressive stress of $102 \mathrm{MPa}$, i.e. $25 \mathrm{MPa}$ above the yield strength of the lattices.

The human osteosarcoma cell line Saos-2 with osteogenic properties was used for the cell culture studies. The cells were maintained in Dulbecco's Modified Eagle's medium supplemented with $10 \%$ foetal bovine serum and antibiotics (50 U/ml penicillin and $50 \mu \mathrm{g} / \mathrm{ml}$ streptomycin). Sterile samples were placed in 24-well cell culture plates, pre-incubated in cell culture medium for $24 \mathrm{~h}$, and then seeded with cells at a density of $5 \times 10^{5}$ cells/sample. As a control, cells were seeded at a density of $1 \times 10^{4}$ cells/well directly on the cell culture plate. Cells were maintained in a $5 \% \mathrm{CO}_{2}$ humidified atmosphere at $37^{\circ} \mathrm{C}$ for up to 14 days with a regular change of the medium. Cell morphology, cell number, cell metabolic activity, alkaline phosphatase (ALP) activity and mineralization were determined in triplicates after 7 and 14 days of culture. Before the assays, the samples were rinsed with phosphate buffer solution and transferred to a new well plate to avoid the interference of the cells growing at the bottom of the culture plate. Cell morphology was observed by scanning electron microscopy (SEM) in dehydrated samples fixed with $10 \%$ formalin and coated with a nanometric carbon layer. Cell number was indirectly quantified as the total content of protein in the samples determined after cell lysis by Bradford assay. The cells in the samples were lysed with $1 \mathrm{ml}$ of $0.1 \%$ Triton X-100. Cell metabolic activity was evaluated using a resazurin assay, measuring the resorufin fluorescence (excitation at $560 \mathrm{~nm}$, emission at $590 \mathrm{~nm}$ ) after $2 \mathrm{~h}$ incubation of cell cultures with $10 \mu \mathrm{g} / \mathrm{ml}$ resazurin using Synergy $\mathrm{H} 4 \mathrm{Hybrid}$ multi-mode microplate reader (Bio-Tek). The ALP activity was quantified with a colorimetric assay kit as the p-nitrophenol 
generated by the cell lysate during the assay. Optical absorbance was measured at $405 \mathrm{~nm}$ using a microplate reader and the results were normalized by cell lysate volume and time of reaction. Mineralization was quantified using Alizarin Red staining extraction in samples fixed with $10 \%$ formalin. The samples were stained with $40 \mathrm{mM}$ Alizarin Red after fixation. After 30 min the samples were washed with distilled water and the absorbed Alizarin Red staining was extracted with $1 \mathrm{ml}$ of $10 \%$ acetic acid. The optical absorbance of the extract was measured at $405 \mathrm{~nm}$ using a microplate reader.

\section{RESULTS AND DISCUSSION}

Figure 1 shows one titanium lattice fabricated by SLM. The lattice is an orthogonal grid with square-like pores between struts observed from the printing plane. The size of the pores, equivalent to the distance between adjacent struts in the same printing plane, was $550 \mu \mathrm{m}$, whereas the diameter of the struts was on average $250 \mu \mathrm{m}$. The pore size is in the top part of the range considered optimal for the in vivo ingrowth of bone and vascularization [7]. The struts show a smooth top surface and rough lateral surfaces due to powder melting and powder particle adhesions, respectively. The thickness of the powder adhered to the struts was heterogeneous, varying between 10 to $150 \mu \mathrm{m}$, but on average showed a thickness around $60 \mu \mathrm{m}$. Moreover, the powder adhesions appear to be mechanically stable since they remained after cleaning the samples in the ultrasonic bath. Powder adhesions are considered as a defect in SLM because they decrease the quality of the surface finish, requiring a post-printing operation such as polishing for their removal. However, the removal of powder adhesions inside the lattices is not a simple task and other SLM parameters that create less amount of attached particles are required. The effects of the powder adhesions on the biocompatibility, osteogenicity and biomechanical performance of the titanium lattices are uncertain, and deserve to be studied in detail, this work addressing the challenge in vitro.
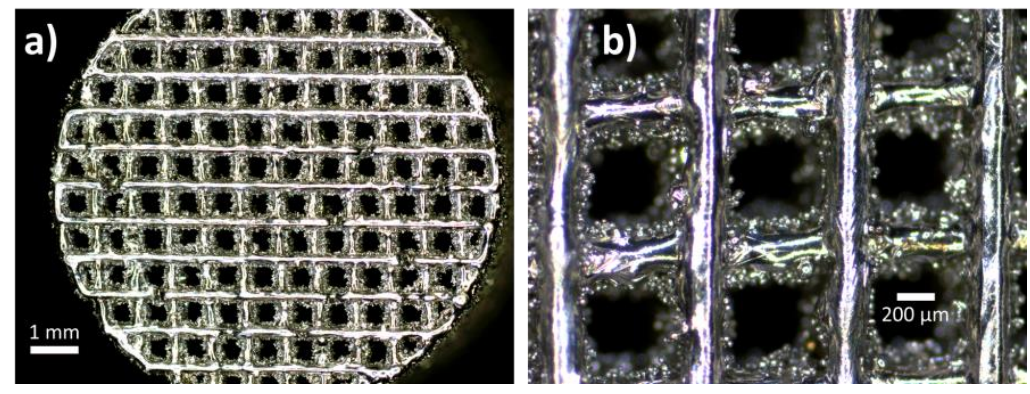

Figure 1 Representative images of the titanium lattices fabricated by SLM, a) general view of the samples from the printing plane and $b$ ) detail of the struts forming the grid. Note the important amount of powder adhesions on the lateral surfaces of the struts

Figure $\mathbf{2} \mathbf{a}$ shows that the microstructure of the titanium lattices corresponded to long acicular needles. The martensite-like morphology is typical for pure titanium processed by SLM due to the high cooling rate during solidification [8]. Therefore, the microstructure can be considered representative of other commercially pure titanium lattices produced by SLM. In addition, the microstructure shows pores with two different sizes, but presumably formed by the same mechanism, i.e. slightly high dynamic viscosity of the melt that in the position of pores prevent the liquid titanium to spread and coalescence on the previously processed layer [1]. Small spherical pores were more frequent in number and were homogeneously distributed, whereas larger pores of irregular shape and heterogeneous size and location were less frequent but they may account for the larger volume fraction. Struts with less porosity can be obtained by increasing the laser power to increase the temperature of the titanium melt, increasing the laser power may also help to melt the powder adhesions producing a smoother surface finishing of the struts. However, the relatively low fraction of pores (around $5 \%$ ) and the absence of non-melted powder particles inside the struts indicate that the laser power used in this work was close to the optimal power; an over-power should be avoided to prevent balling phenomena. 

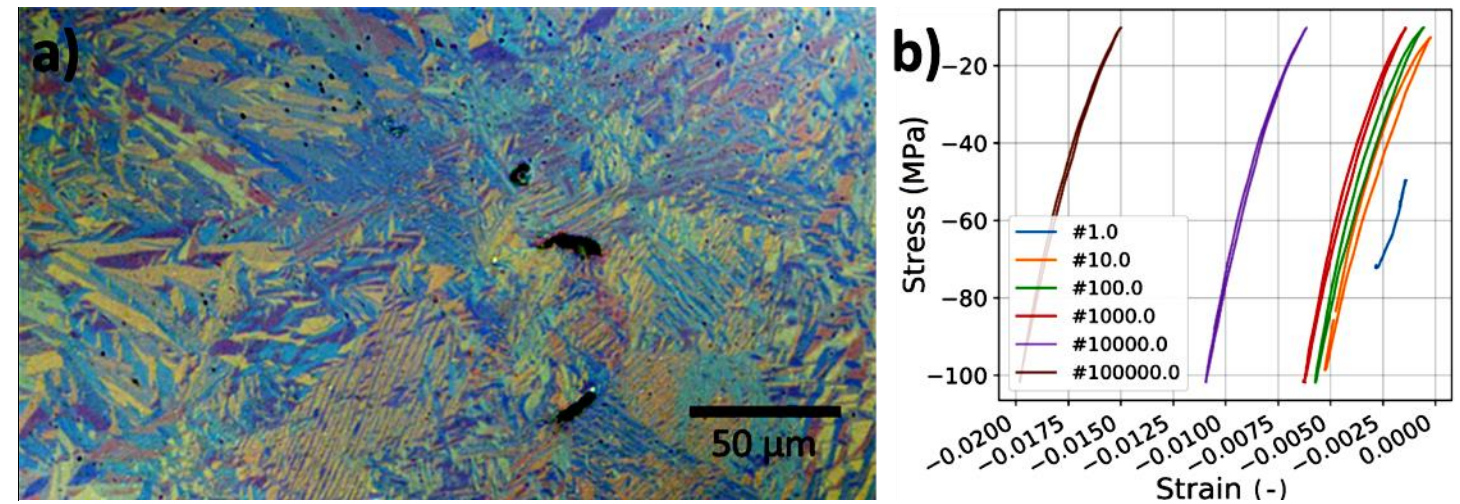

Figure 2 a) Microstructure of the titanium lattices fabricated by SLM and b) stress-strain hysteresis loops during cyclic testing

The yield strength $(76.8 \pm 1.1 \mathrm{MPa})$ of the lattices was high enough for the repair of load-bearing bone defects, and the effective elastic modulus $(6.8 \pm 0.1 \mathrm{GPa})$ was within the stiffness range of trabecular bone (1-10 GPa), being adequate to avoid the stress shielding effect at the bone-implant interface. Despite progressing ratcheting (Figure $\mathbf{2 b}$ ), the lattices were reliable under cycling loading, showing no evidence of permanent structural damage after $5 \times 10^{5}$ cycles, with the dissipated energy density stabilized at $\sim 10 \mathrm{~kJ} / \mathrm{m}^{3}$ per cycle. Thus, it appears that the powder adhesions and pores inside the struts did not significantly reduce fatigue strength at the applied stress level, but their effect on fatigue behaviour should be analysed in future in more detailed studies.

The quantification of the total content of protein in the samples shows that the number of Saos-2 cells increased between 7 and 14 days of culture (Figure 3a). The proliferation was higher in the titanium lattices than in the control (standard cell culture plate) as the protein content increases 3 -fold against to 1.6-fold. The difference attributed to the larger area available in the lattices for cell proliferation in comparison to the limited area of the well of the cell culture plate.
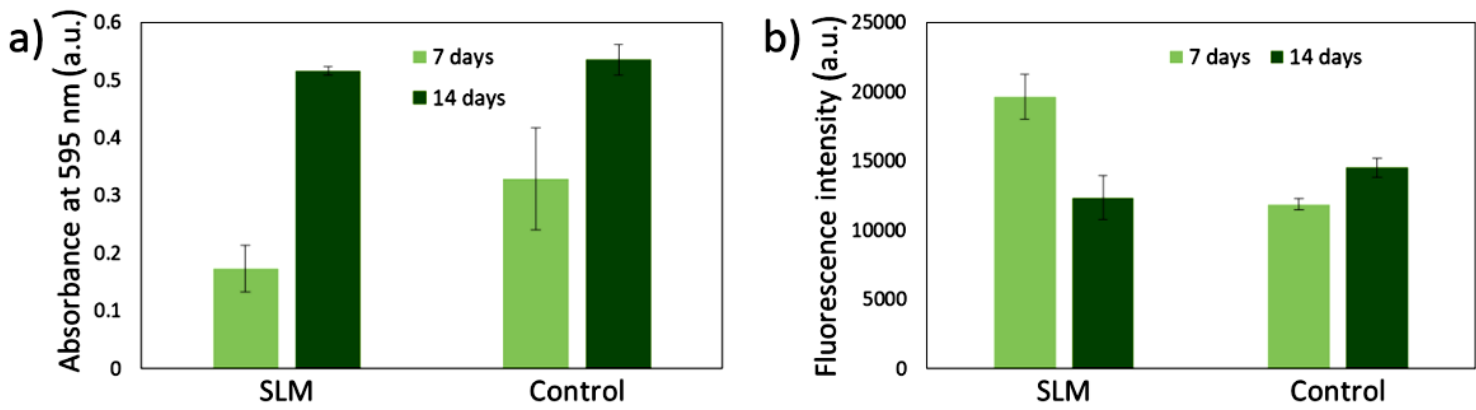

Figure 3 Osteoblasts proliferation, a) total content of protein and b) cell metabolic activity

The cell metabolic activity increased with culture time in the control, reflecting the active proliferation of the cells and consequently their viability (Figure $\mathbf{3 b}$ ). In contrast, the cell metabolic activity significantly decreased in the titanium lattices between 7 and 14 days of culture (Figure $\mathbf{3 b}$ ). The reduction of the cell metabolic activity does not necessarily mean low cell viability or cell damage due to titanium. Cell dormancy is also a cause for low cell metabolic activity evaluated by the reduction of resazurin salt [9]. Furthermore, the quiescent state is one of the three possible final states for mature osteoblast becoming bone lining cells $[10,11]$. The other two alternatives are differentiation to osteocytes or apoptosis. Unlike proliferative osteoblasts, the bone lining cells have a slender and flat morphology in vivo characterising the quiescent bone surfaces [10].

The visualization of the cells growing in direct contact with the titanium lattices further confirmed the cytocompatibility of the material (Figure 4). The cells did not show apoptotic morphology. In contrast, they 
were spread on the struts. Cells were mostly located at the powder adhesion at day 7, but also some cells were located on the smooth part of the struts (Figures 4a-c). The number of visible cells increased on day 14

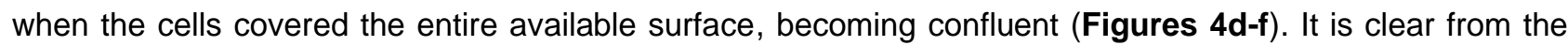
colonization of the struts that the lattices were not harmful to the cells. Therefore, the low number of cells in the active cell division cycle explains the reduction of the cell metabolic activity. Moreover, the cells showed different morphology depending on the zone of the struts where they had grown. The morphology of the cells mimicked the morphology of the bone lining cells in the smooth part of the struts, i.e. the cells were spread, slender and flat (Figures $\mathbf{4 b}, \mathbf{e}$ ). Most of the cells were so thin that they looked like dark patches on the surface and were identified in the images by the typical spindle morphology (Figures 4a, c, e). Cells exhibited an elongated morphology in the powder adhesions, normally bridging two powder particles or linking the smooth surface with one particle adhered (Figures 4c, f).
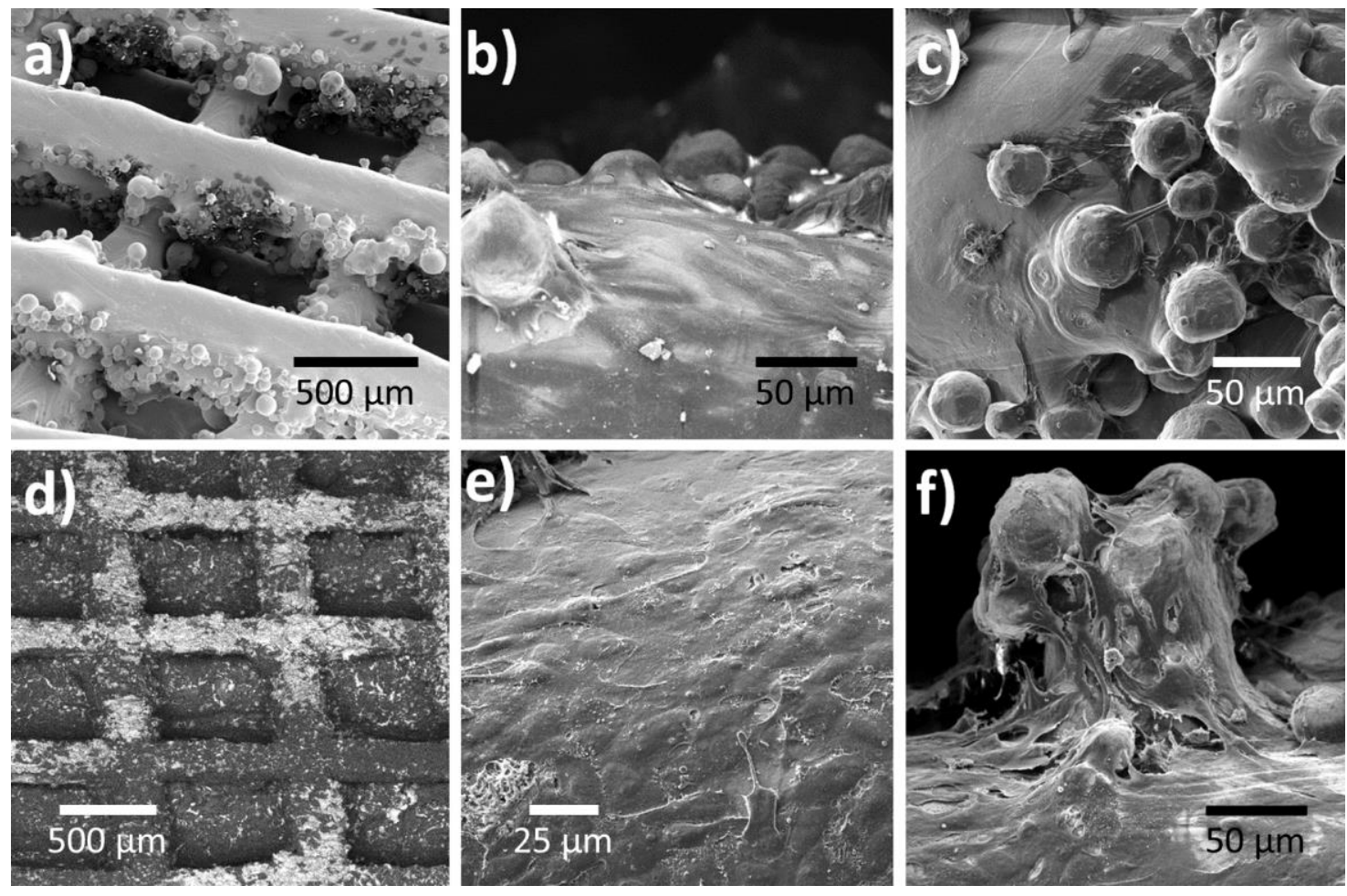

Figure 4 Osteoblasts morphology after 7 days (a-c) and 14 days (d-f) of culture in titanium lattices

The osteogenic capacity of the cells was tested by the ALP activity assay. ALP activity is an osteogenic marker because it provides phosphate ions for mineralization. ALP activity increased with culture time (Figure 5a), corresponding to the higher number of proliferating osteoblasts, which synthesize ALP. This agreed with lower ALP activity in confluent cells in the titanium lattice. The detection of the ALP activity was indicative of the presence of viable cells with the ability to synthesize ALP, further confirming the cytocompatibility of the titanium lattices.

A second confirmation of the osteoblastic phenotype was the quantification of mineralization by the extraction of the Alizarin Red staining (Figure 5b). Saos-2 are mature osteoblasts with the ability to produce extracellular calcium deposits, the ability that was not impaired when cultured in the titanium lattices fabrication by SLM. In particular, the powder adhesions did not show any negative effect on the in vitro proliferation and maturation of Saos-2 cells. In contrast, they appear to be favourable for cell adhesion. The lack of toxicity is an additional advantage that adds to the possibility to simultaneously match the porosity and mechanical properties of cancellous bone by computer-aided design and subsequently implement the titanium lattice fabrication by additive manufacturing. 

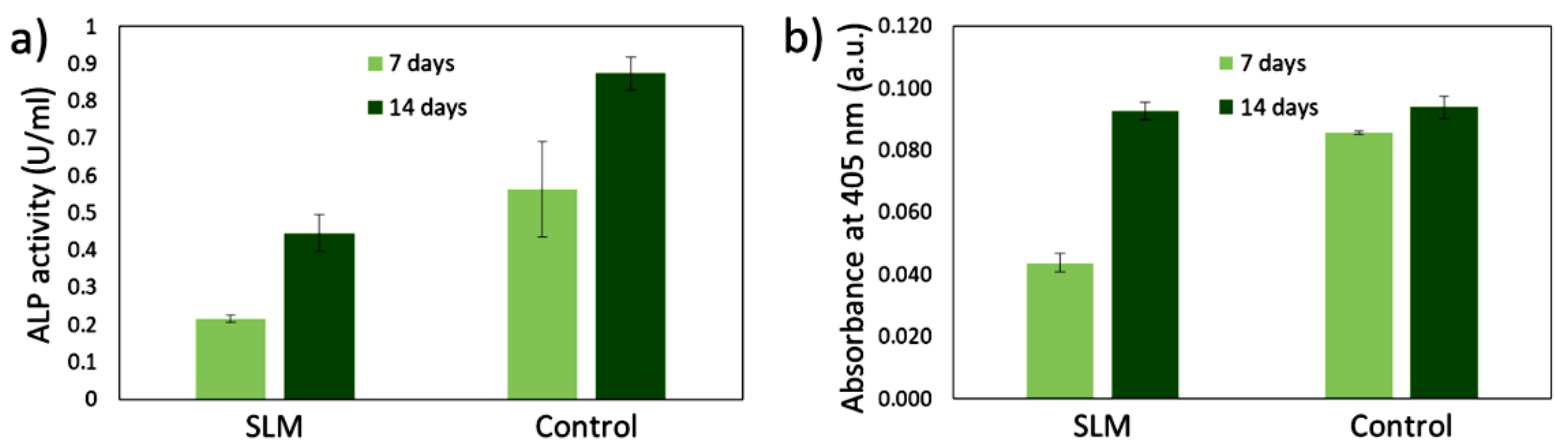

Figure 5 Osteoblasts maturation, a) ALP activity and b) mineralization quantified by the extraction of Alizarin Red staining

\section{CONCLUSION}

The microstructure of the fabricated lattices is in agreement with the martensite-like microstructure typical for commercially pure titanium processed by SLM. Therefore, the Saos-2 behaviour can be considered representative of the osteoblastic response to commercially pure titanium parts produced by SLM. The results show that the titanium lattices fabricated by SLM did not impair the proliferation and maturation of osteoblastlike cells. Saos-2 cells proliferated and covered the entire available surface, becoming confluent and quiescent. Moreover, the cells exhibited a spread, slender and flat morphology that mimicked the morphology of the bone lining cells. The cytocompatibility of the titanium lattices together with the achievable lattice complexity enable a range of orthopaedic applications, including customised load-bearing implants with stiffness optimised for biomechanical compatibility with bone. A limitation of the titanium lattices is the low osteogenic activity in the as-built state. Although the structural design can improve the osteogenic activity, additional surface treatments may be required to promote fast bone growth and implant osseointegration.

\section{ACKNOWLEDGEMENTS}

This work was supported by the Czech Science Foundation (grant 19-22662S). L.H.T. (OBM*) acknowledges CONACYT and Programa de Maestría y Doctorado en Ciencias Médicas, Odontológicas y de la Salud for the scholarship number 331090. A.K. acknowledges the Brno Ph.D. Talent scholarship founded by the Brno City Municipality and the project CEITEC VUT/FAST-J-217305. Z.K. acknowledges funds from the Faculty of Medicine, Masaryk University to junior researcher (ROZV/28/LF/2020).

\section{REFERENCES}

[1] GU, D.D., MEINERS, W., WISSENBACH, K., POPRAWE, R. Laser additive manufacturing of metallic components: materials, processes and mechanisms. Int. Mater. Rev. 2012, vol. 57, pp. 133-164.

[2] KAUR, M., SINGH, K. Review on titanium and titanium based alloys as biomaterials for orthopaedic applications. Mater. Sci. Eng. C. 2019, vol. 102, pp. 844-862.

[3] HUISKES, R., WEINANS, H., RIETBERGEN, B.V. The relationship between stress shielding and bone resorption around total hip stems and the effects of flexible materials. Clin. Orthop. Relat. Res. 1992, vol. 274, pp. 124-134.

[4] EL ELMI, A., MELANCON, D., ASGARI, M., LIU, L., PASINI, D. Experimental and numerical investigation of selective laser melting-induced defects in Ti-6Al-4V octet truss lattice material: the role of material microstructure and morphological variations. J. Mat. Res. 2020, vol. 35, pp. 1900-1912.

[5] YAN, C., HAO, L., HUSSEIN, A. Ti-6AI-4V triply periodic minimal surface structures for bone implants fabricated via selective laser melting. J. Mech. Beh. Biomed. Mat. 2015, vol. 51, pp. 61-73.

[6] HAN, C., LI Y., WANG, Q. Continuous functionally graded porous titanium scaffolds manufactured by selective laser melting for bone implants. J. Mech. Beh. Biomed. Mat. 2018, vol. 80, pp. 119-127. 
[7] PEREZ, R., MESTRES, G. Role of pore size and morphology in musculo-skeletal tissue regeneration. Mater. Sci. Eng. C. 2016, vol. 61, pp. 922-939.

[8] ATTAR, H., CALLIN, M., ZHANG, L.C., SCUDINO, S., ECKERT, J. Manufacture by selective laser melting and mechanical behavior of commercially pure titanium. Mater. Sci. Eng. A. 2014, vol. 593, pp. 170-177.

[9] DIAZ, M., HERRERO, M., GARCÍA, L.A., QUIROS, C. Flow cytometry: a high-throughput technique for microbial bioprocess characterization. In: MOO-YOUNG, M. Comprehensive biotechnology (Second Edition). Academic Press, 2011, pp. 967-981.

[10] BROWN, J.L., KUMBAR, S.G., LAURENCIN, C.T. Bone tissue engineering. In: RATNER, B.D., HOFFMAN, A.S., SCHOEN, F.J., LEMONS, J.E. Biomaterials science (Third Edition). Academic Press, 2013, pp. 1194-1214.

[11] BALDINI, N., CENNI, E., CIAPETTI, G., GRANCHI, D., SAVARINO, L. Bone repair and regeneration. In: PLANELL, J.A., BEST, S.M., LACROIX, D., MEROLLI, A. Bone repair biomaterials. Woodhead Publishing, 2009, pp. 69-105. 